\title{
Rifampicin does not significantly affect the expression of small heterodimer partner in primary human hepatocytes
}

\author{
Petr Pavek $^{1}$, Lucie Stejskalova ${ }^{1,2}$, Lucie Krausova ${ }^{1}$, Michal Bitman $^{1}$, Radim Vrzal ${ }^{3}$ and Zdenek Dvorak ${ }^{3}$ \\ 'Department of Pharmacology and Toxicology, Faculty of Pharmacy in Hradec Kralove, Charles University in Prague, Hradec Kralove, Czech Republic \\ 2 Institute of Molecular and Translation Medicine, Palacky University in Olomouc, Olomouc, Czech Republic \\ ${ }^{3}$ Department of Cell Biology and Genetics, Faculty of Science, Palacky University in Olomouc, Olomouc, Czech Republic
}

\section{Edited by:}

Miia Turpeinen, University of Oulu, Finland

Reviewed by:

Miia Turpeinen, University of Oulu,

Finland

Paavo Honkakoski, University of

Eastern Finland, Finland

*Correspondence:

Petr Pavek, Department of Pharmacology and Toxicology, Faculty of Pharmacy in Hradec Kralove, Charles University in Prague,

Heyrovskeho 1203, Hradec Kralove, CZ-500 05, Czech Republic.

e-mail:petr.pavek@faf.cuni.cz
The small/short heterodimer partner (SHP, NROB2) is a nuclear receptor corepressor lacking a DNA binding domain. SHP is induced by bile acid-activated farnesoid X receptor (FXR) resulting in CYP7A1 gene suppression. In contrast, Pregnane $X$ receptor (PXR) activation by its ligands was recently suggested to inhibit SHP gene transactivation to maximize the induction of PXR target genes. However, there are also conflicting reports in literature whether PXR or rodent Pxr activation down-regulates SHP/Shp expression. Moreover, the PXR-mediated regulation of the SHP gene has been studied only at the SHP mRNA and transactivation (gene reporter assay) levels. In this study, we studied the effect of rifampicin, a prototype PXR ligand, on SHP mRNA, and protein expression in three primary human hepatocyte cultures. We found that SHP mRNA is not systematically down-regulated in hepatocyte in culture after $24 \mathrm{~h}$ treatment with rifampicin. Consistently, we did not observe down-regulation of SHP protein in primary human hepatocytes after 24 and $48 \mathrm{~h}$ of incubation with rifampicin. We can conclude that although we observed slight down-regulation of SHP mRNA and protein in several hepatocyte preparations, the phenomenon is unlikely critical for PXR-mediated induction of its target genes.

Keywords: SHP, cytochrome P450, induction, PXR, CYP3A4

\section{INTRODUCTION}

The small/short heterodimer partner (SHP, NR0B2) is a member of the nuclear receptor family (nuclear receptor subfamily 0 , group $\mathrm{B}$, member 2 ) with the highest expression in the liver. SHP is an unusual nuclear receptor since it lacks a conventional DNA binding domain and the main function of SHP appears to be repression of other nuclear receptors via competition with their coactivators (Seol et al., 1996; Bavner et al., 2005) http://en.wikipedia.org/wiki/Small_heterodimer_partner cite_note-pmid16275121-2.

Recently, SHP has been shown to be involved in the control of bile acid biosynthesis. The first and rate limiting step of bile acid biosynthesis is catalyzed by cytochrome P450 $7 \alpha$ (CYP7 $\alpha ; 7 \alpha$-hydroxylase) in the liver. Two different laboratories have concomitantly found that chenodeoxycholic acid (CDCA) via farnesoid X receptor (FXR) induces the expression of SHP, which then binds to and inhibits LRH-1, an orphan receptor that regulates CYP7 $\alpha$ expression (Goodwin et al., 2000; Lu et al., 2000). SHP is thus a negative nuclear receptor that is induced by bile acid-activated FXR and inhibits the CYP7A1 gene expression, a key regulatory gene in bile acid synthesis.

Pregnane X receptor (PXR, NR1I2) is a ligand-activated transcription factor, which is activated by a broad range of lipophilic compounds including a myriad of drugs, by some synthetic and endogenous steroids, certain bile acids, and natural products. PXR is referred to as a "master regulator" or "xenosensor" for the metabolism and clearance of diverse endogenous and exogenous compounds (Tirona and Kim, 2005; Pavek and Dvorak, 2008; Biswas et al., 2009).

CYP3A4 enzyme is the most important enzyme of the cytochrome P450 superfamily, which metabolizes almost $50 \%$ of commonly used drugs (Li et al., 1995; MartinezJimenez et al., 2007; Pavek and Dvorak, 2008). Importantly, CYP3A4 is the most important and well-studied target gene of PXR (Goodwin et al., 1999; Martinez-Jimenez et al., 2007; Pavek et al., 2010). Consistently, CYP3A4 is highly expressed in key sites of drug disposition such as in the liver and small intestine. In addition, PXR regulates the expression of several other important drug/xenobioticmetabolizing enzymes such as CYP2C9, CYP2B6, CYP2C19, CYP3A5, UGT1A1, and SULT2A1 as well as drug transporters such as MDR1 (P-glycoprotein) and MRP2 (Pavek and Dvorak, 2008).

Small/short heterodimer partner has been reported to suppress transcriptional activity of PXR in various cell models in vitro (Wang et al., 2002; Ourlin et al., 2003; Li and Chiang, 2005) and in Shp wild-type mice, but not in Shp null mice in vivo (Wang et al., 2002). In cell-based transient transfection reporter assays, the overexpression of SHP produced a dose-dependent inhibition of both mouse Pxr and human PXR transcriptional activities. This inhibition was escaped by the overexpression of steroid receptor coactivator-1 (SRC1, nuclear receptor coactivator-1, NCOA1) suggesting competition of the coactivator with SHP corepressor on 
PXR (Ourlin et al., 2003). In addition, SHP blocks PXR interaction with HNF4 $\alpha$ but does not affect PXR and PGC- $1 \alpha$ interaction (Li and Chiang, 2006). In addition SHP blocks PXR binding to CYP3A4 promoter DNA (Ourlin et al., 2003; Li and Chiang, 2006). In a positive feedback loop, PXR was supposed to inhibit SHP gene transactivation and SHP mRNA expression to maximize the PXR induction of the CYP3A4 gene in human hepatocytes ( $\mathrm{Li}$ and Chiang, 2006).

The aim of this study was to examine in detail the effect of rifampicin on SHP expression in PXR-mediated transactivation of the main drug-metabolizing enzyme, CYP3A4, in primary human hepatocytes. In particular, we examined the effect of a prototype PXR ligand rifampicin on SHP protein expression in several primary human hepatocyte preparations.

\section{MATERIALS AND METHODS CELL LINES AND PRIMARY HUMAN HEPATOCYTES}

The human MZ-Hep1 hepatocarcinoma cell line (kindly donated by Dr. Ramiro Jover, Hospital La Fe, Valencia, Spain) was maintained in antibiotic-free DMEM supplemented with 10\% Fetal bovine serum (FBS) and $1 \mathrm{mM}$ sodium pyruvate. FBS was purchased from PAA (Pasching, Austria). Other chemicals and cell culture media were purchased from Sigma-Aldrich (St. Louis, MO, USA). The final concentration of DMSO in the culture media was $0.1 \%(\mathrm{v} / \mathrm{v})$ in all experiments.

Long-term human hepatocytes in monolayer were purchased from Biopredic International, Rennes, France, and were maintained according to the protocols provided by Biopredic. The medium was exchanged for serum-free medium the day after delivery, and the culture was allowed to stabilize for an additional 6-24 h prior to treatments.

LH28 and LH29 primary human hepatocyte preparations were isolated, cultivated, and treated as described in our previous papers (Bachleda et al., 2009; Dvorak et al., 2010). Our tissue preparation protocol was designed in accordance with the requirements issued by local ethical commissions in the Czech Republic. In addition, we used three commercial preparations of Long-term human hepatocytes in monolayer: Batch HEP220466 (75-year-old female suffering from hepatocellular carcinoma), Batch HEP220465 (63year-old male with liver metastases), and Batch HEP220492 (66year-old female with hepatic metastases; Biopredic International, Rennes, France).

\section{DNA CONSTRUCTS}

A chimeric p3A4-luc reporter construct containing the basal promoter $(-362 /+53)$ and the distal xenobiotic responsive enhancer module $(-7836 /-7208)$ of the CYP3A4 gene $5^{\prime}$-flanking region was described elsewhere (Cerveny et al., 2007). The expression plasmids for PXR and SHP receptors, pSG5-hPXR, and pSG5hSHP, were kindly provided by Dr. S. Kliewer (University of Texas, TX, USA). pRL-TK was purchased from Promega and the empty pSG5 vector was purchased from Stratagene.

\section{TRANSIENT TRANSFECTION AND LUCIFERASE GENE REPORTER ASSAYS}

All transient transfection assays were carried out in MZ-Hepl cells, as described previously (Pavek et al., 2010).

\section{QUANTITATIVE REAL-TIME RT-PCR}

Total RNA isolation and quantitative real-time RT-PCR (qRT-PCR) analyses of CYP3A4 (hCYP3A4_Q2) and SHP (hNR0B2_Q2) mRNA expression in primary human hepatocytes were performed by employing commercial assays from GeneriBiotech (Hradec Kralove, Czech Republic) as described elsewhere (Pavek et al., 2007, 2010; Svecova et al., 2008). HPRT (hHPRT_Q3) housekeeping gene expression levels were used as normalization controls. Experiments were performed in triplicates (i.e., three individual cell samples) and each cDNA sample has been analyzed as triplicate in one RT-PCR run.

\section{IMMUNOBLOTTING}

The relative abundance of each specific protein in $25-50 \mu \mathrm{g}$ of whole cell lysate was determined by Western blot analysis, as described previously (Pospechova et al., 2009). Anti-SHP (H-160: sc-30169; dilution 1:250), anti-human CYP3A4 (HL3: sc53850; 1:2000), and goat polyclonal anti-actin antibodies (clone I-19: 1616; a loading control) were purchased from Santa Cruz Biotechnology, Inc. (Santa Cruz, USA). Densitometric analyses have been performed to semi-quantify the expression of the tested proteins.

\section{STATISTICAL ANALYSES}

All data are expressed as the mean \pm SD. Differences between the groups were compared with Student's paired two-tailed $t$-test. Kruskal-Wallis test with Dunn's Multiple Comparison post hoc test and One-way analysis of variance (ANOVA) with Tukey's Multiple Comparison test were use to analyze data in Figure 3. All statistical analyses were performed using GraphPad Prism 4 Software. $p$ Value $<0.05$ was considered statistically significant.

\section{RESULTS}

RIFAMPICIN DOES NOT SYSTEMATICALLY SUPPRESS SHP MRNA GENE EXPRESSION IN PRIMARY HUMAN HEPATOCYTES

First, we examined whether rifampicin, a prototype PXR ligand, affects the expression of SHP mRNA in primary human hepatocytes. We found that rifampicin $(10 \mu \mathrm{M})$ had no statistically significant effect on SHP mRNA expression on three primary human hepatocyte cultures (analyzed with Student's paired $t$-test, Figure 1A), although in individual preparations we observed the effect of rifampicin on SHP mRNA expression. At the same time, we evaluated the expression of the main PXR target gene, CYP3A4. We found that rifampicin $(10 \mu \mathrm{M})$ significantly $(p<0.01)$ induced expression of CYP3A4 mRNA after $24 \mathrm{~h}$ in the same primary human hepatocyte preparations (analyzed with Student's paired $t$-test, Figure 1B). The effect of rifampicin on CYP3A4 mRNA expression reflects high inter-individual variation in response to PXR inducers in various hepatocyte preparations and in human population.

\section{RIFAMPICIN DOES NOT SYSTEMATICALLY AFFECT SHP PROTEIN EXPRESSION IN PRIMARY HUMAN HEPATOCYTES}

In next experiments, we examined the effect of rifampicin $(10 \mu \mathrm{M})$ on SHP protein expression in hepatocytes treated with rifampicin employing Western blotting analysis. Rifampicin did not significantly decrease SHP protein expression after 24 or $48 \mathrm{~h}$ treatment in either human hepatocyte preparation (Figures 2A,B). 


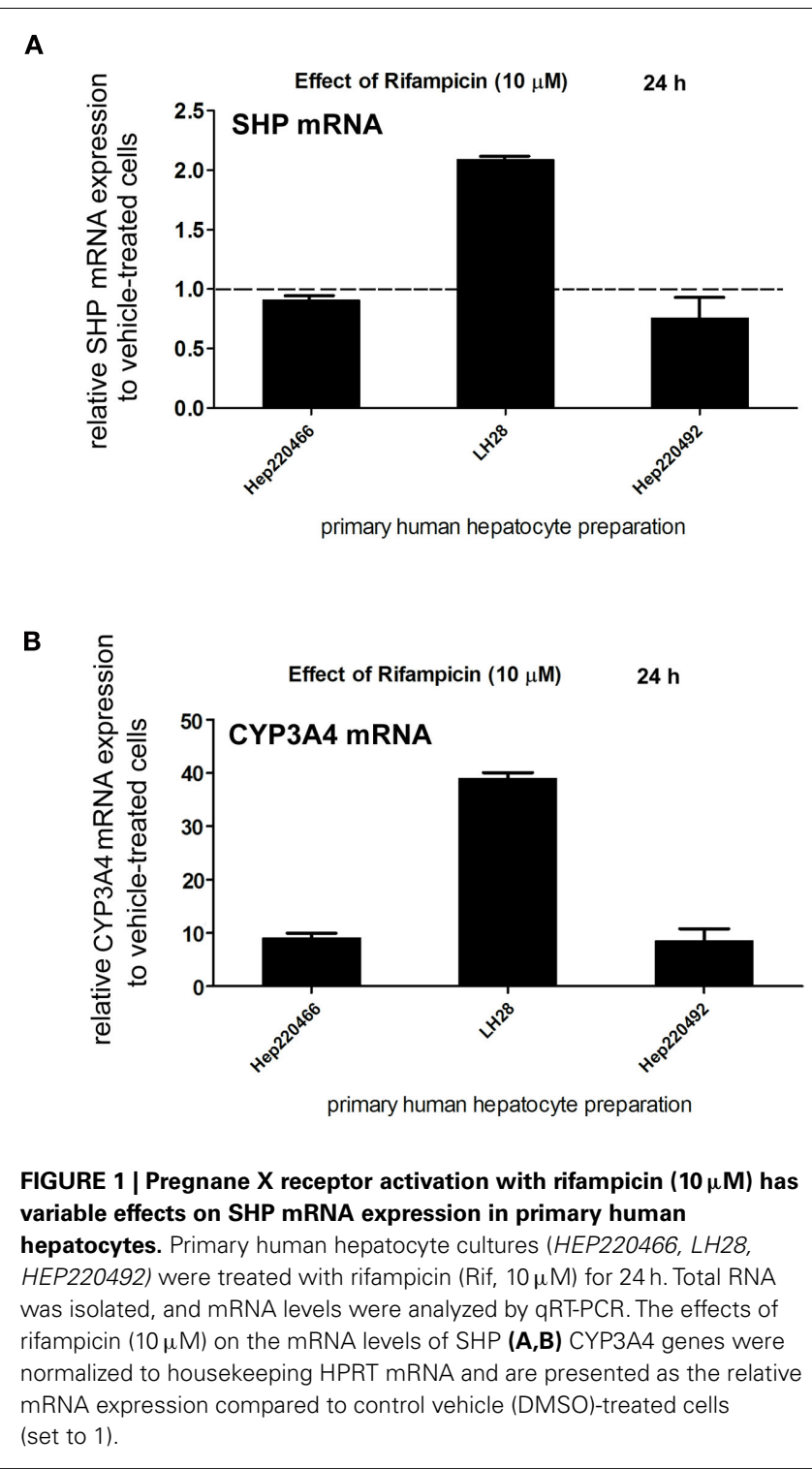

\section{THE EFFECTS OF SHP OVEREXPRESSION ON CYP3A4 TRANSACTIVATION IN GENE REPORTER ASSAYS}

In next transient transfection gene reporter experiments with p3A4-luc construct, we examined whether SHP suppresses CYP3A4 in gene reporter assays in hepatocellular carcinoma cell line MZ-Hep1 cells. The MZ-Hep1 cell line was confirmed to expresses SHP protein (Figure 2B). Consistently with reported data in other liver-derived cell lines (Ourlin et al., 2003; Li and Chiang, 2006), we observed that overexpression of SHP significantly abolished rifampicin-mediated activation of the CYP3A4 construct $(p<0.01$, ANOVA) with Tukey's Multiple Comparison test; Figure 3).

\section{DISCUSSION}

Recently, Li and Chiang proposed an elegant model of PXRmediated transactivation of CYP3A4 in human hepatocytes (Li and Chiang, 2006). This model supposes that activated PXR

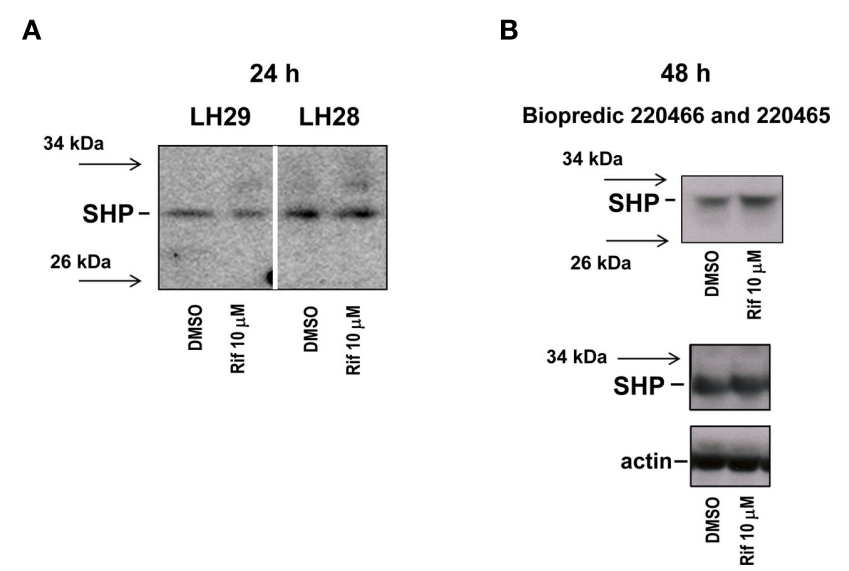

FIGURE 2 | Pregnane $X$ receptor activation with rifampicin $(10 \mu \mathrm{M})$ has no effect on SHP protein expression in primary human hepatocytes. Primary human hepatocyte cultures were treated with rifampicin (Rif, $10 \mu \mathrm{M}$ ) for 24 (A) or $48 \mathrm{~h}$ (B). SHP protein levels were analyzed by Western blotting with specific antibody.

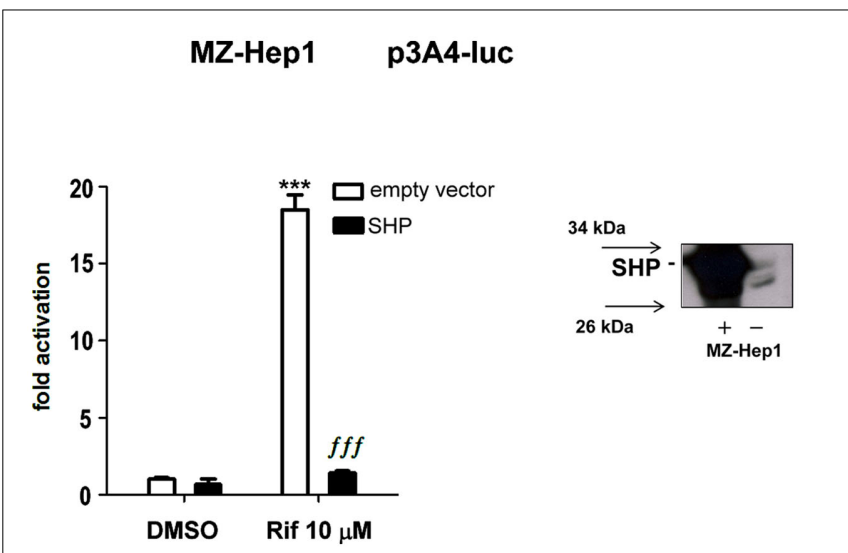

FIGURE 3 | Small/short heterodimer partner overexpression abolishes CYP3A4 transactivation in gene reporter assay in MZ-Hep1 cells. MZ-Hep1 cells were cotransfected with p3A4-luc reporter construct (200 ng per well in 48-well plate), expression constructs for PXR ( $50 \mathrm{ng}$ per well), or expression construct for SHP (50 ng, or appropriate amount of pSG5 empty vector). After $24 \mathrm{~h}$ incubation with rifampicin $(10 \mu \mathrm{M})$, triplicates of cell samples were lysed and analyzed for firefly normalized to Renilla luciferase activity. Data represent the mean of three independent experiments and are shown as fold activation of normalized luciferase activity relative to solvent $(0.1 \%$ DMSO) controls (set to 1$)$. Statistically significant to vehicle (DMSO)-treated cells cotransfected under the same experimental conditions ${ }^{* * *} p<0.01$; statistically significant to rifampicin-treated cells cotransfected under the same experimental conditions ${ }^{\int f f} p<0.01$ (Kruskal-Wallis test with Dunn's Multiple Comparison post hoc test and ANOVA with Tukey's Multiple Comparison test). SHP protein levels in MZ-Hep1 cells were analyzed by Western blotting with specific antibody.

trans-represses SHP expression and since SHP competes with HNF4 $\alpha$ and SRC1 coactivators for binding to PXR, this feedback loop maximizes PXR-mediated induction of the CYP3A4 gene. 
Nevertheless, earlier reports did not find any statistically significant effects of PXR and rodent ortholog Pxr activation, either by specific ligands or using engineered animal models, on SHP or Shp transcript expression (Ourlin et al., 2003; Rosenfeld et al., 2003; Hartley et al., 2004; Guzelian et al., 2006; Bailey et al., 2011) or on SHP binding to PXR target genes promoters employing chromatin immunoprecipitation (ChIP; Hariparsad et al., 2009). In primary human hepatocytes, Ourlin et al. (2003) first reported no effect of rifampicin on SHP mRNA expression.

In our experiments, we did not observe significant effect of rifampicin on SHP expression, although slight decrease was observed in some experiments. Notably, we observed hepatocyte preparation-dependent effect of rifampicin on SHP mRNA expression (Figure 1A). These data might indicate inter-individual effect of PXR activation on SHP expression in hepatocytes. We can also consider some unspecified dietary, physiological, or environmental aspects of inter-individual response to PXR activation in terms of SHP expression.

Indeed, in population, CYP3A4 displays high inter-individual variability in expression and catalytic activity in the liver. To date,

\section{REFERENCES}

Bachleda, P., Vrzal, R., Pivnicka, J., Cvek, B., and Dvorak, Z. (2009). Examination of zolpidem effects on AhRand PXR-dependent expression of drug-metabolizing cytochromes P450 in primary cultures of human hepatocytes. Toxicol. Lett. 191, 74-78.

Bailey, I., Gibson, G. G., Plant, K., Graham, M., and Plant, N. (2011). A PXR-mediated negative feedback loop attenuates the expression of CYP3A in response to the PXR agonist pregnenalone-16alphacarbonitrile. PLOS ONE 6, el6703. doi:10.1371/journal.pone.0016703

Bavner, A., Sanyal, S., Gustafsson, J. A., and Treuter, E. (2005). Transcriptional corepression by SHP: molecular mechanisms and physiological consequences. Trends Endocrinol. Metab. 16, 478-488.

Biswas, A., Mani, S., Redinbo, M. R., Krasowski, M. D., Li, H., and Ekins, S. (2009). Elucidating the 'Jekyll and Hyde' nature of PXR: the case for discovering antagonists or allosteric antagonists. Pharm. Res. 26, 1807-1815.

Cerveny, L., Svecova, L., Anzenbacherova, E., Vrzal, R., Staud, F., Dvorak, Z., Ulrichova, J., Anzenbacher, P., and Pavek, P. (2007). Valproic acid induces CYP3A4 and MDR1 gene expression by activation of constitutive androstane receptor and pregnane X receptor pathways. Drug Metab. Dispos. 35, 1032-1041.

Dvorak, Z., Vrzal, R., Starha, P., Klanicova, A., and Travnicek, Z. (2010). Effects of dinuclear copper(II) complexes with 6-(benzylamino)purine derivatives on AhR and PXR dependent expression of cytochromes P450 CYP1A2 and CYP3A4 genes in primary cultures of human hepatocytes. Toxicol. In vitro 24, 425-429.

Goodwin, B., Hodgson, E., and Liddle, C. (1999). The orphan human pregnane $\mathrm{X}$ receptor mediates the transcriptional activation of CYP3A4 by rifampicin through a distal enhancer module. Mol. Pharmacol. 56, 1329-1339.

Goodwin, B., Jones, S. A., Price, R. R., Watson, M. A., McKee, D. D., Moore, L. B., Galardi, C., Wilson, J. G., Lewis, M. C., Roth, M. E., Maloney, P. R., Willson, T. M., and Kliewer, S. A. (2000). A regulatory cascade of the nuclear receptors FXR, SHP-1, and LRH-1 represses bile acid biosynthesis. Mol. Cell 6, 517-526.

Guzelian, J., Barwick, J. L., Hunter, L., Phang, T. L., Quattrochi, L. C., and Guzelian, P. S. (2006). Identification of genes controlled by the pregnane $\mathrm{X}$ receptor by microarray analysis of mRNAs from pregnenolone 16alpha-carbonitriletreated rats. Toxicol. Sci. 94, 379-387.

Hariparsad, N., Chu, X., Yabut, J., Labhart, P., Hartley, D. P., Dai, X., and Evers, R. (2009). Identification of pregnane-X receptor target genes and coactivator and corepressor binding to promoter elements in human hepatocytes. Nucleic Acids Res. 37, 1160-1173.

Hartley, D. P., Dai, X., He, Y. D., Carlini, E. J., Wang, B., Huskey, S. E., Ulrich, R. G., Rushmore, T. H., Evers, R., and Evans, D. C. (2004). Activators of

however, no single nucleotide polymorphisms of the CYP3A4 gene coding region or its promoter region have been found as the direct cause of the variability (Martinez-Jimenez et al., 2007). It is therefore supposed that transcription activity of nuclear receptors including SHP might be the cause of CYP3A4 expression variability in the liver and in the intestine.

We conclude that the physiological role of SHP in regulation of CYP3A4 induction needs to be further studied in a larger population of human hepatocyte preparations. In addition, our results again confirm that SHP is an important negative regulator of CYP3A4 transactivation that may contribute to inter-individual variability in CYP3A4 hepatic expression.

\section{ACKNOWLEDGMENTS}

This work was supported by Grant Agency of Charles University No. 118708/C, the Czech Scientific Agency (Grant No. 303/07/0128 to P. Pavek), and by SVV-2011-263-003 project to L. Stejskalova and M. Bitman. The authors would like to thank to all of our kind donors for providing us with the necessary cDNA constructs to complete this work.

the rat pregnane $\mathrm{X}$ receptor differentially modulate hepatic and intestinal gene expression. Mol. Pharmacol. 65, 1159-1171.

Li, A. P., Kaminski, D. L., and Rasmussen, A. (1995). Substrates of human hepatic cytochrome P450 3A4. Toxicology 104, 1-8.

Li, T., and Chiang, J. Y. (2005). Mechanism of rifampicin and pregnane $\mathrm{X}$ receptor inhibition of human cholesterol 7 alpha-hydroxylase gene transcription. Am. J. Physiol. Gastrointest. Liver Physiol. 288, G74G84.

Li, T., and Chiang, J. Y. (2006). Rifampicin induction of CYP3A4 requires pregnane $\mathrm{X}$ receptor cross talk with hepatocyte nuclear factor 4alpha and coactivators, and suppression of small heterodimer partner gene expression. Drug Metab. Dispos. 34, 756-764.

Lu, T. T., Makishima, M., Repa, J. J., Schoonjans, K., Kerr, T. A., Auwerx, J., and Mangelsdorf, D. J. (2000). Molecular basis for feedback regulation of bile acid synthesis by nuclear receptors. Mol. Cell 6, 507-515.

Martinez-Jimenez, C. P., Jover, R., Donato, M. T., Castell, J. V., and Gomez-Lechon, M. J. (2007). Transcriptional regulation and expression of CYP3A4 in hepatocytes. Curr. Drug Metab. 8, 185-194.

Ourlin, J. C., Lasserre, F., Pineau, T., Fabre, J. M., Sa-Cunha, A., Maurel, P., Vilarem, M. J., and Pascussi, J. M. (2003). The small heterodimer partner interacts with the pregnane $\mathrm{X}$ receptor and represses its transcriptional activity. Mol. Endocrinol. 17, 1693-1703.
Pavek, P., Cerveny, L., Svecova, L., Brysch, M., Libra, A., Vrzal, R., Nachtigal, P., Staud, F., Ulrichova, J., Fendrich, Z., and Dvorak, Z. (2007). Examination of glucocorticoid receptor alpha-mediated transcriptional regulation of $\mathrm{P}$ glycoprotein, CYP3A4, and CYP2C9 genes in placental trophoblast cell lines. Placenta 28, 1004-1011.

Pavek, P., and Dvorak, Z. (2008). Xenobiotic-induced transcriptional regulation of xenobiotic metabolizing enzymes of the cytochrome P450 superfamily in human extrahepatic tissues. Curr. Drug Metab. 9 , 129-143.

Pavek, P., Pospechova, K., Svecova, L., Syrova, Z., Stejskalova, L., Blazkova, J., Dvorak, Z., and Blahos, J. (2010). Intestinal cellspecific vitamin D receptor (VDR)mediated transcriptional regulation of CYP3A4 gene. Biochem. Pharmacol. 79, 277-287.

Pospechova, K., Rozehnal, V., Stejskalova, L., Vrzal, R., Pospisilova, N., Jamborova, G., May, K., Siegmund, W., Dvorak, Z., Nachtigal, P., Semecky, V., and Pavek, P. (2009). Expression and activity of vitamin D receptor in the human placenta and in choriocarcinoma BeWo and JEG3 cell lines. Mol. Cell. Endocrinol. 299, 178-187.

Rosenfeld, J. M., Vargas, R. Jr., Xie, W., and Evans, R. M. (2003). Genetic profiling defines the xenobiotic gene network controlled by the nuclear receptor pregnane X receptor. $\mathrm{Mol}$. Endocrinol. 17, 1268-1282.

Seol, W., Choi, H. S., and Moore, D. D. (1996). An orphan nuclear 
hormone receptor that lacks a DNA binding domain and heterodimerizes with other receptors. Science 272, 1336-1339.

Svecova, L., Vrzal, R., Burysek, L., Anzenbacherova, E., Cerveny, L., Grim, J., Trejtnar, F., Kunes, J., Pour, M., Staud, F., Anzenbacher, P., Dvorak, Z., and Pavek, P. (2008). Azole antimycotics differentially affect rifampicin-induced pregnane $\mathrm{X}$ receptor-mediated CYP3A4 gene expression. Drug Metab. Dispos. 36, 339-348.
Tirona, R. G., and Kim, R. B. (2005). Nuclear receptors and drug disposition gene regulation. J. Pharm. Sci. 94, 1169-1186.

Wang, L., Lee, Y. K., Bundman, D., Han, Y., Thevananther, S., Kim, C. S., Chua, S. S., Wei, P., Heyman, R. A., Karin, M., and Moore, D. D. (2002). Redundant pathways for negative feedback regulation of bile acid production. Dev. Cell 2, 721-731.

Conflict of Interest Statement: The authors declare that the research was conducted in the absence of any commercial or financial relationships that could be construed as a potential conflict of interest.

Received: 19 August 2011; paper pending published: 14 September 2011; accepted: 01 January 2012; published online: 19 January 2012.

Citation: Pavek P, Stejskalova L, Krausova L, Bitman M, Vrzal $R$ and Dvorak $Z$ (2012) Rifampicin does not significantly affect the expression of small heterodimer partner in primary human hepatocytes. Front. Pharmacol. 3:1. doi: 10.3389/fphar.2012.00001

This article was submitted to Frontiers in Drug Metabolism and Transport, a specialty of Frontiers in Pharmacology. Copyright (C) 2012 Pavek, Stejskalova, Krausova, Bitman, Vrzal and Dvorak. This is an open-access article distributed under the terms of the Creative Commons Attribution Non Commercial License, which permits non-commercial use, distribution, and reproduction in other forums, provided the original authors and source are credited. 